\title{
Abstract \\ Attitudes towards learning communication skills and factors affecting learning communication skills of final year medical students
}

Wickramasinghe $\mathrm{RS}^{1^{*}}$, Karunarathne $\mathrm{A}^{1}$, Perera $\mathrm{M}^{1}$, Thalgaspitiya $\mathrm{S}^{2}$, Liyanage $\mathrm{A}^{2}$

${ }^{1}$ Professorial Surgical Unit, Teaching Hospital Anuradhapura, Sri Lanka

${ }^{2}$ Department of Surgery, Faculty of Medicine and Allied Sciences, Rajarata University of Sri Lanka

\begin{abstract}
Background

It is widely accepted that medical students should acquire and demonstrate proficiency in communication by the end of their undergraduate education although many students do not consider it as important as the clinical skills. This study identifies the attitudes of medical students towards, and the factors affecting learning of communication skills.

Methods

Descriptive cross sectional study was carried out with 162 final year medical students of Rajarata university of Sri Lanka. Their attitudes towards learning communication skills and factors affecting learning communication skills were assessed using a self-administered questionnaire with modified Communication Skills Assessment Scale incorporated with likert scale from a previous Sri Lankan study. Positive attitude scale (PAS) and negative attitude scale (NAS) questions were analyzed separately.

Results

The mean age of the students was 25.8 years. $53.7 \%(n=87)$ of students were females. Vast majority were Sinhalese $(93.7 \%)$ and Buddhists (84.6\%). Quarter $(25.7 \%)$ of the students believed their communication skills were below average and $46.3 \%$ thought they are average. One third (34\%) were comfortable when communicating with patients in a second language. Majority thought that the communication skills must be taught. $65.4 \%$ of the students asked for a separate module on communication skills in their curriculum. $73.5 \%$ wanted it to be done before clinicals. $34 \%$ opted for audio visual examples, and 35.8\% thought role plays with colleagues were better. $61.7 \%$ thought that the busy work schedule in the prof unit prevent them from learning communication skills.

\section{Conclusions}

The medical students have understood the importance of learning communication skills for their medical carrier and they are interested in learning them. Therefore the medical education should put more weight on the communication skills adopting novel education strategies.
\end{abstract}

Key words: Learning communication skills; Medical students; Undergraduate

Copyright:@ 2015 Wickramasinghe RS et al. This is an open access article distributed under the Creative Commons Attribution License, which permits unrestricted use, distribution, and reproduction in any medium, provided the original work is properly cited.

\footnotetext{
* Correspondence : sujanthe@yahoo.com
}

Cite this abstract as: Wickramasinghe RS, Karunarathne A, Perera M, Thalgaspitiya S, Liyanage A. Attitudes towards learning communication skills and factors affecting learning communication skills of final year medical students. Anuradhapura Medical Journal 2015;9 (2Supp):S09.

DOI: http://dx.doi.org/10.4038/amj.v9i2Supp.7558 


\section{Submit your next Manuscript to}

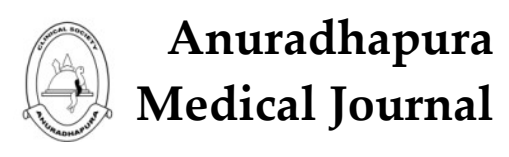

Submit your manuscript at

http://amj.sljol.info/ 